\title{
Variable Conductance Heat Pipe Cooling of Stirling Convertor and General Purpose Heat Source
}

\author{
Calin Tarau ${ }^{1}$, Carl Schwendeman ${ }^{1}$, William G. Anderson ${ }^{1}$, Peggy A. Cornell ${ }^{2}$ \\ and Nicholas A. Schifer ${ }^{2}$ \\ ${ }^{1}$ Advanced Cooling Technologies, Inc., 1046 New Holland Ave. Lancaster, PA 17601 U.S.A. \\ 717-295-6066,Calin.Tarau@1-ACT.com \\ ${ }^{2}$ NASA John H. Glenn Research Center, 21000 Brookpark Rd. MS 301-2 Cleveland, OH 44135 U.S.A.
}

\begin{abstract}
In a Stirling Radioisotope Power System (RPS), heat must be continuously removed from the General Purpose Heat Source (GPHS) modules to maintain the modules and surrounding insulation at acceptable temperatures. The Stirling convertor normally provides this cooling. If the Stirling convertor stops in the current system, the insulation is designed to spoil, preventing damage to the GPHS at the cost of an early termination of the mission. An alkali-metal Variable Conductance Heat Pipe (VCHP) can be used to passively allow multiple stops and restarts of the Stirling convertor. In a previous NASA SBIR Program, Advanced Cooling Technologies, Inc. (ACT) developed a series of sodium VCHPs as backup cooling systems for Stirling RPS. The operation of these VCHPs was demonstrated using Stirling heater head simulators and GPHS simulators. In the most recent effort, a sodium VCHP with a stainless steel envelope was designed, fabricated and tested at NASA Glenn Research Center (GRC) with a Stirling convertor for two concepts; one for the Advanced Stirling Radioisotope Generator (ASRG) back up cooling system and one for the Long-lived Venus Lander thermal management system. The VCHP is designed to activate and remove heat from the stopped convertor at a $19{ }^{\circ} \mathrm{C}$ temperature increase from the nominal vapor temperature. The $19{ }^{\circ} \mathrm{C}$ temperature increase from nominal is low enough to avoid risking standard ASRG operation and spoiling of the Multi-Layer Insulation (MLI). In addition, the same backup cooling system can be applied to the Stirling convertor used for the refrigeration system of the Long-lived Venus Lander. The VCHP will allow the refrigeration system to: 1) rest during transit at a lower temperature than nominal; 2) pre-cool the modules to an even lower temperature before the entry in Venus atmosphere; 3) work at nominal temperature on Venus surface; 4) briefly stop multiple times on the Venus surface to allow scientific measurements. This paper presents the experimental results from integrating the VCHP with an operating Stirling convertor and describes the methodology used to achieve their successful combined operation.
\end{abstract}

\section{Introduction}

Advanced Stirling Radioisotope Generators (ASRG) are an attractive energy system for select space missions, and with the addition of a VCHP, they become even more versatile. The ASRG system is powered through thermal energy from decaying radioisotopes acting as General Purpose Heat Sources (GPHS). A Stirling engine converts the thermal energy to electrical energy and cools the GPHS. [1] The Stirling convertor must operate continuously to maintain acceptable temperatures of the GPHS and protect their cladding. The addition of alkali metal VCHPs allows the Stirling to cycle on and off during a mission and can be used as a backup cooling system. The benefits of being able to turn the Stirling off (VCHP on) are: reducing the Stirling fatigue, creep on the convertor heater head, and reducing vibrations for sensitive measurements. Heater head creep would be reduced by lowering the temperature of the system using the VCHP. The VCHP addition should also increase the efficiency of the Stirling by providing a uniform temperature across the heater head.

A potential Stirling mission supplemented with a VCHP is the Long-lived Venus Lander, where a long duration mission is desired in the Venus environment. The VCHP will provide longer component life with the ability to turn off the Stirling during certain time periods of the mission. The Venus Lander VCHP will have four key functions for the mission: 1) allow the convertor to rest during transit at a lower temperature than the nominal one; 2) pre-cool the 
modules to an even lower temperature before entry into the Venus atmosphere; 3) work at nominal temperature in Venus environment; 4) allow multiple brief stoppages of the convertor on the Venus surface to allow scientific measurements. The four key functions for the Venus Lander and the ASRG backup cooling concept were demonstrated with a Stirling convertor provided by NASA Glenn.

\section{Concept Introduction}

The conceptual VCHP for a Stirling convertor has four critical components; an evaporator, a first condenser, a second condenser and a Non-Condensable Gas (NCG) reservoir as shown in Figure 1. The VCHP is atypical because of the presence of two condensers. The working fluid is sodium and is shown in orange starting at the GPHS and ending at the front. The NCG is shown in tan starting at the front and ending in the reservoir. The VCHP evaporator interfaces with the GPHS modules and transfers thermal energy to one of the condensers. The first condenser is located at the Stirling's heater head and is active only if the Stirling convertor is operating. The second condenser is a radiator between the heater head and the NCG reservoir that is active when the Stirling is off as shown in Figure 1. The NCG reservoir is located after the second condenser. The VCHP was tested for two scenarios: the ASRG backup cooling concept and the Venus Lander four-feature concept. The two tested concepts for the VCHP are described below.

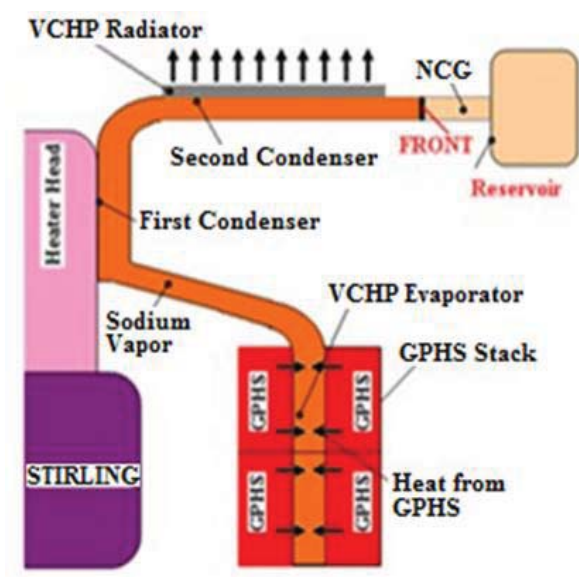

Figure 1. VCHP interfaced with the GPHS and Stirling convertor.

\section{ASRG Backup Cooling Concept}

The ASRG backup cooling concept is the simplest concept and involves turning the Stirling on and off at intervals of a given duration. The ASRG concept is shown in Figure 2, where the GPHS module interfaces directly with the Stirling heater head. The VCHP is shown in red and blue. The red depicts the hot sodium vapor and the blue represents the colder NCG. The VCHP wraps annularly around the heat collector attached to the Stirling heater head. The predicted location of the front is shown in Figure 2 for each stage. Heat is input to the Stirling when it is operational and the front is before the VCHP radiator (second condenser) as shown on the left in Figure 2. When the Stirling is turned off, the sodium vapor temperature will rise slightly and sweep the NCG out of the second condenser for utilization as a radiator. In the ASRG backup cooling concept, the cold side adapter flange (CSAF) would be used as the heat sink. The tested VCHP prototype radiates to ambient air for simplicity. The front will recede when the Stirling is turned back on and the vapor temperature will drop returning the system to the initial state. The Stirling will be cycled on and off to demonstrate repeatability and the recovery of the system parameters.

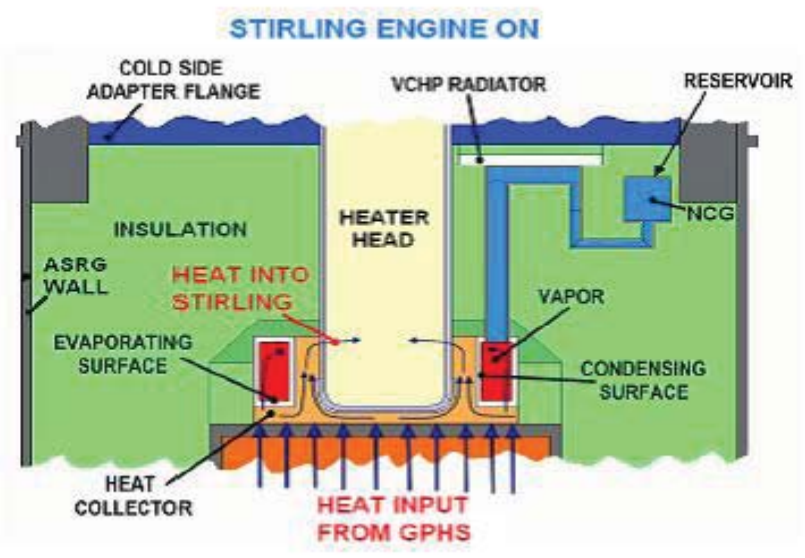

a)

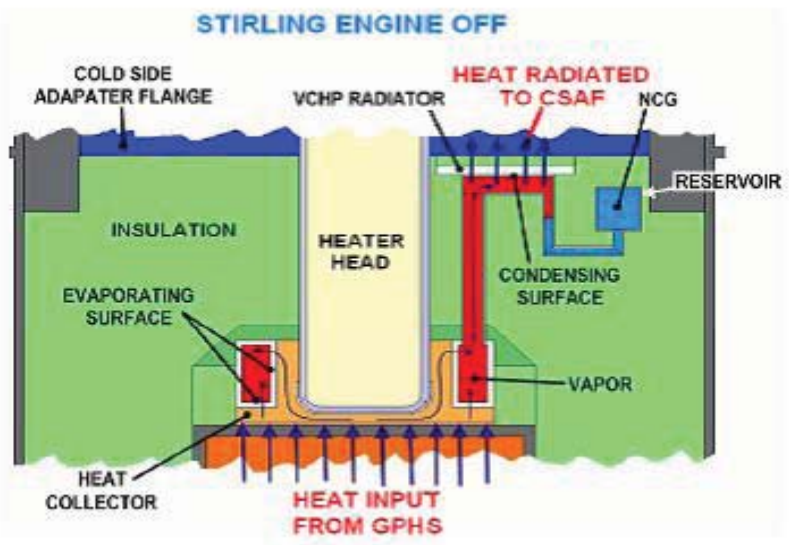

b)

Figure 2. ASRG backup cooling concept - front location for Stirling on a) and off b). [2] 


\section{Venus Lander Four-Feature Concept}

The Four-feature concept models the VCHP operating on a Stirling powered mission to Venus. The four features are described below:

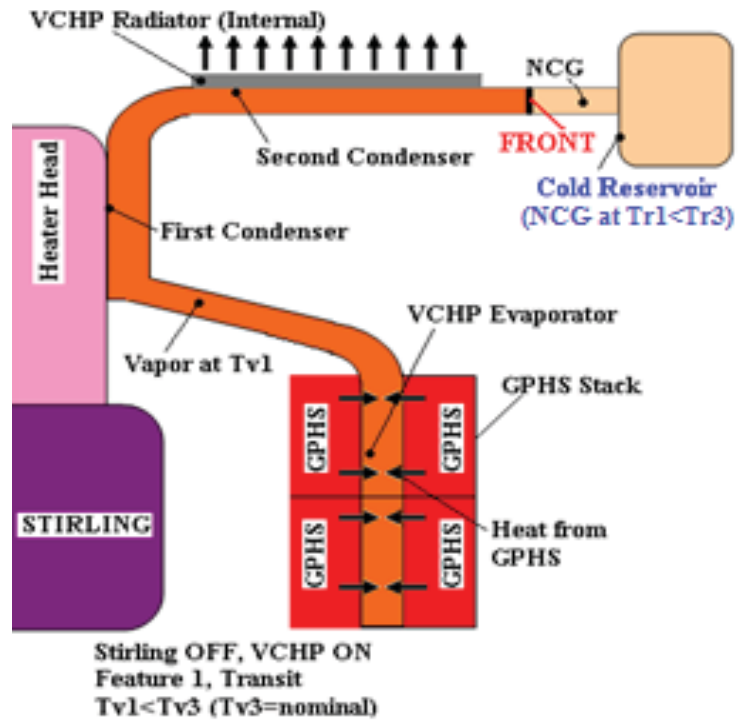

a)

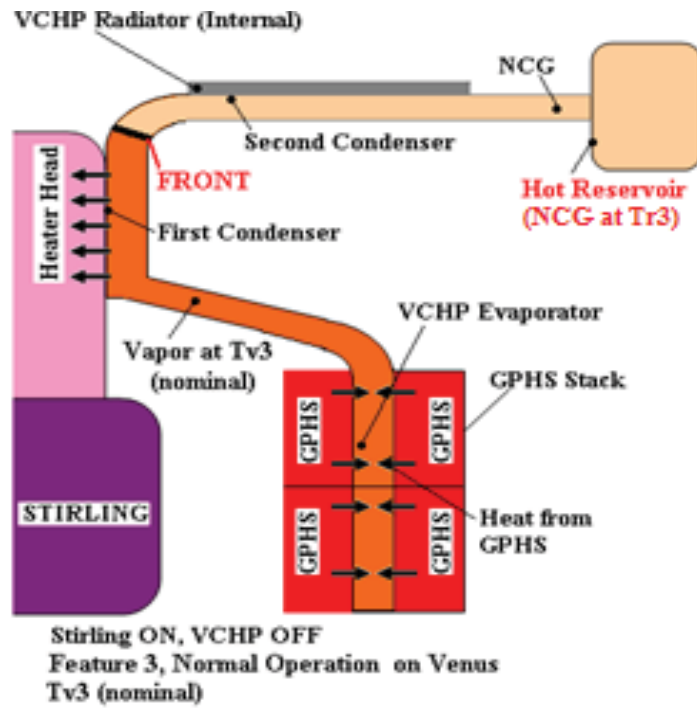

c)

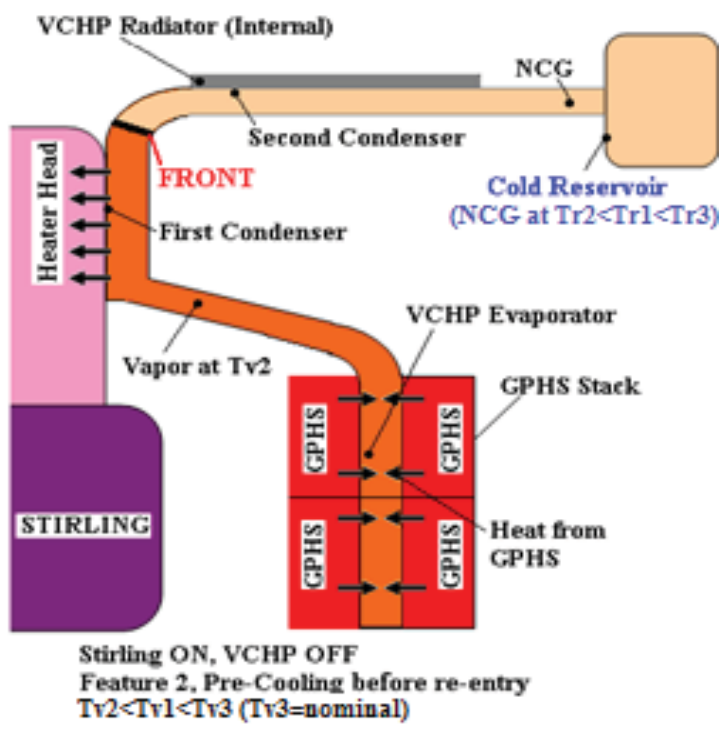

b)

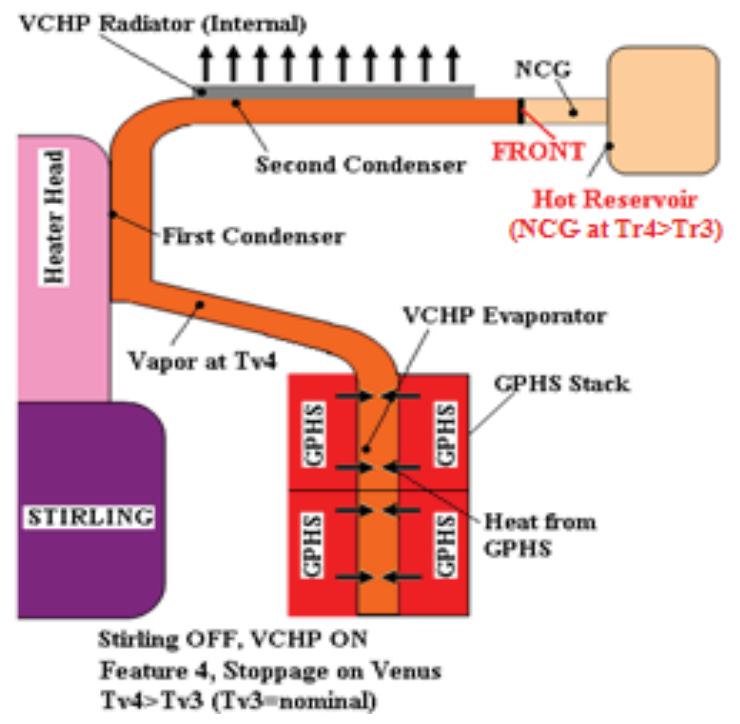

d)

Figure 3. Schematic of principle for the Venus Lander four-feature concept a) Stirling OFF during transit to Venus with a cold reservoir. b) Pre-cooling the GPHS modules before re-entry. c) Stirling operating on Venus with a hot reservoir. d) Stirling stopped on Venus. [3]

- Feature 1. Transit. (Figure 3a) The Stirling is off (rests) at lower temperature during transit to Venus to reduce creep on the system. In this stage, the VCHP radiator (second condenser) is active and the VCHP reservoir is cold from heat losses to space. Vapor temperature is represented as Tv1.

- Feature 2. Pre-cooling. (Figure 3b) The Lander is shortly going to enter Venus's atmosphere and pre-cooling of the system is desired. The Stirling convertor is turned on and the system is cooled to the lowest temperature of the mission (Tv2). 
- Feature 3. Normal Operation on Venus. (Figure 3c) The Lander is in the Venus environment with the Stirling operating at its nominal temperature. The vapor temperature is represented as Tv3, the front is before the second condenser and the NCG reservoir is warmed by heat gains from the atmosphere.

- Feature 4. Stoppage on Venus. (Figure 3d) The Lander is in the Venus environment with the Stirling off because of vibration sensitive measurements. The second condenser is active. At the end of this feature, the Stirling convertor is restarted and all the parameters return to the values that correspond to Feature 3.

\section{Stirling Convertor}

The Stirling convertor used for this test was an Advanced Stirling Convertor (ASC-1HS \#2) developed by Sunpower, Inc. under contract to NASA Glenn Research Center (GRC) as a technology development project. The $80 \mathrm{~W}_{\mathrm{e}}$ class ASC-1 HS \#2 arrived at GRC in November 2007 and has accumulated over 6,500 hours of operation in GRC's Stirling Research Lab. It is a hermetically sealed unit, with the exception of the helium fill tube, that can reach $850{ }^{\circ} \mathrm{C}$ with a high-strength cast superalloy $247 \mathrm{LC}$ heater head that allows for higher hot-end temperatures. The convertor is shown in Figure 4 in the vertical (heater head up) test position. Figure 4 also illustrates the conceptual integration of the VCHP with the convertor.

The ASC heater head is covered by a brazed Nickel 201 cylinder known as the heat collector. Substantial effort for test preparation focused on obtaining an accurate fit between the outside diameter (OD) of the heat collector and the inside diameter (ID) of the VCHP. At GRC, the OD of the convertor's heat collector was ground to $59.72 \mathrm{~mm}(+0.000$ $\mathrm{mm},-0.025 \mathrm{~mm}$ ) to accurately fit within the ID of the heat pipe. At ACT, the VCHP was machined to an ID of at least $59.79 \mathrm{~mm}(+0.025 \mathrm{~mm},-0.000 \mathrm{~mm})$. Final measurements with calipers showed that both surfaces still displayed some slight high spots, however, after dry-run mating between the two parts, four shims of $0.076 \mathrm{~mm}\left(0.003\right.$ ") thickness $90^{\circ}$ were able to be fit within the clearance gap. Boron nitride paste was used to coat the OD of the ASC heat collector and the ID of the VCHP to allow for thermal transfer between the two surfaces and to prevent galling during VCHP removal.

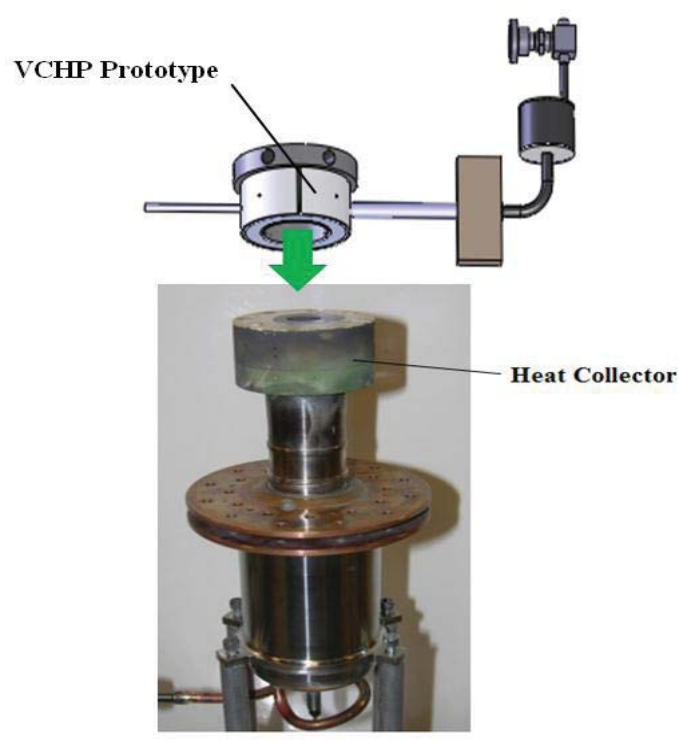

Figure 4. VCHP integration with the Stirling

\section{VCHP Prototype Design}

The VCHP design was dictated by the Stirling's geometry and particularly by the OD and the height of the heat collector. An annular VCHP configuration that fits over the heat collector was selected to maximize heat transfer area. The exploded assembly and final assembly of the first prototype are shown in Figures 5 and 6 . The VCHP has two primary segments, the annular portion and the pipe portion. The annular portion of the VCHP fits completely over the Stirling's heat collector. Extending out of the annular part of the VCHP is the radiator (second condenser) and the NCG reservoir. The extension was necessary to put the radiator and NCG reservoir outside of the insulated area for testing. The radiator is exposed to ambient air and the temperature of the reservoir is controlled for the experiment. The details of the VCHP operation are given below. 


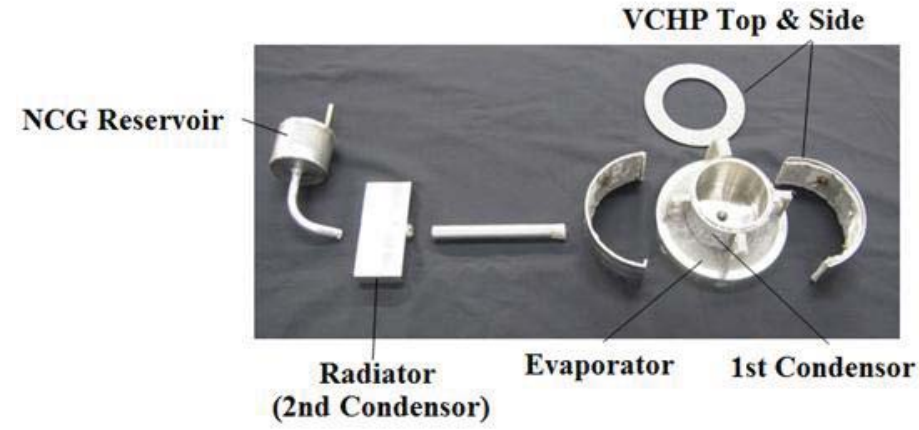

Figure 5. VCHP components before assembly

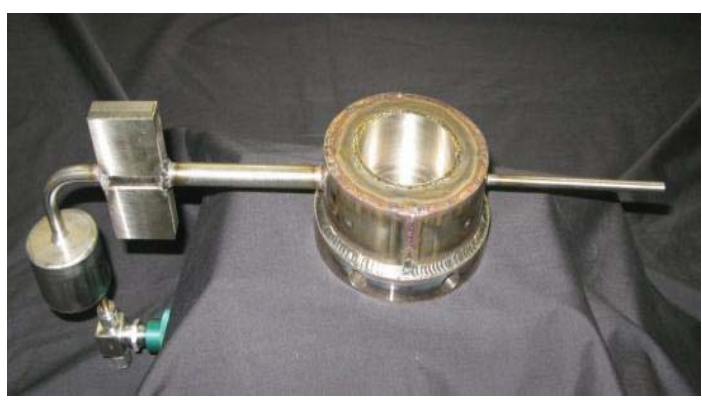

Figure 6. Assembled VCHP.

The removable VCHP test apparatus on the Stirling is shown in Figure 7. The VCHP is designed to transfer heat from a heat source either to the Stirling or to the environment depending on the operation of the Stirling convertor and the VCHP reservoir temperature. The prototype is heated through the base with cartridge heaters simulating a GPHS module as shown Figure 7.
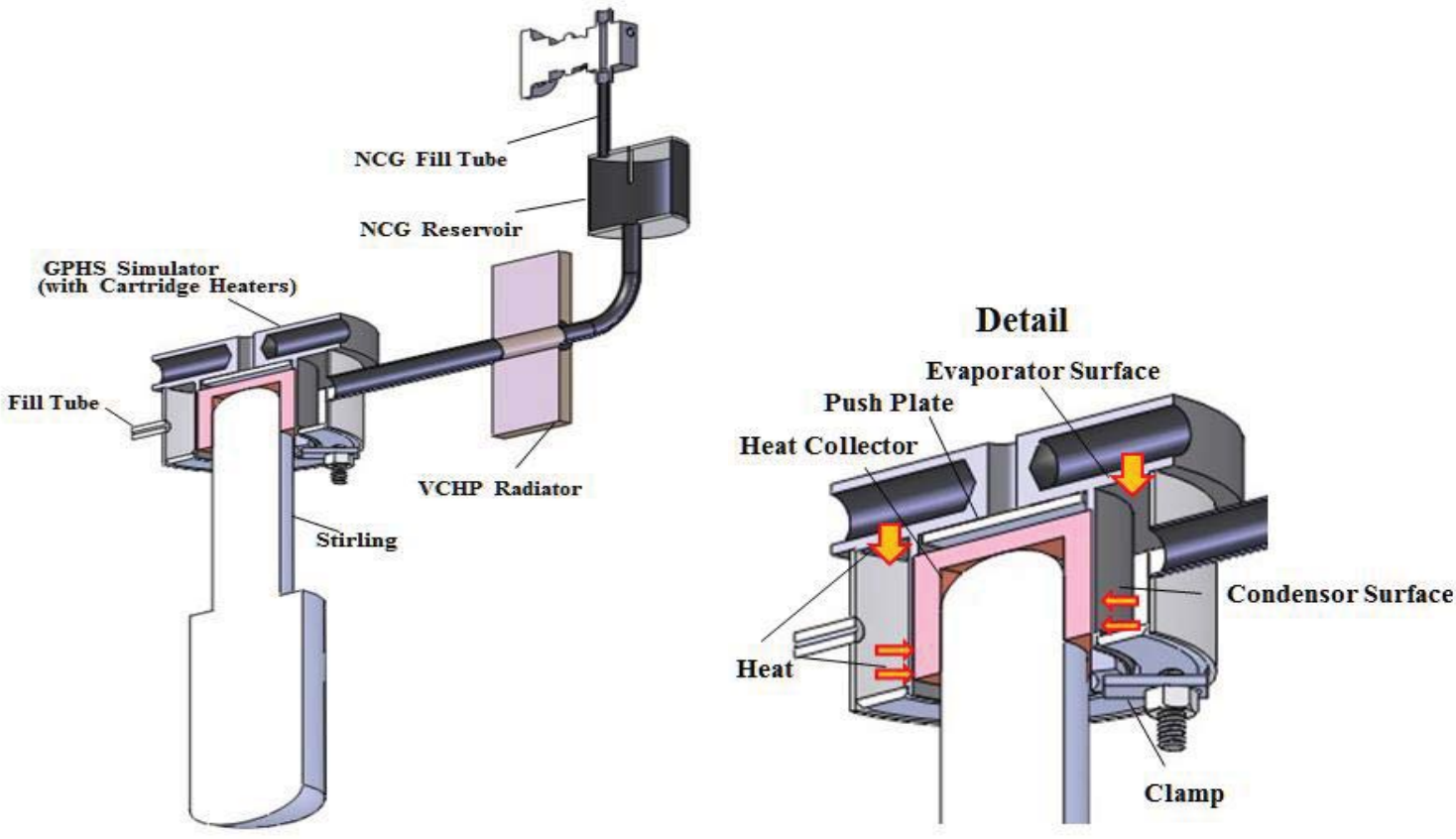

Figure 7. VCHP connected to Stirling convertor.

The VCHP working fluid evaporates on the top of the heater block absorbing the input heat. When the Stirling convertor is operating, the annular VCHP transfers heat to the heater head through the first condensing surface as shown in Figure 7. When the Stirling engine is not operating, the VCHP working fluid condenses at the VCHP radiator (second condensing surface) transferring the heat to ambient. The top of the heat collector is insulated from the GPHS simulator by an air gap to direct the incoming heat to the cylindrical heat transfer area. The top of the heat collector rests on a small rim inside of the VCHP. The inner wall of the VCHP was minimized to reduce the heat transfer down the wall and to reduce the thermal resistance from the sodium vapor to the heater collector.

\section{Experimental Configuration}

The testing setup is shown in Figure 8 with the VCHP and Stirling convertor assembled. The VCHP mounts and clamps onto the Stirling heater head after which the insulation and the Stirling's insulation cover are installed. The test position is vertical with the heater head up to accommodate the fixture of the Stirling convertor. The final combined hardware (with insulation and thermocouples hooked up) is shown in Figure 9. 


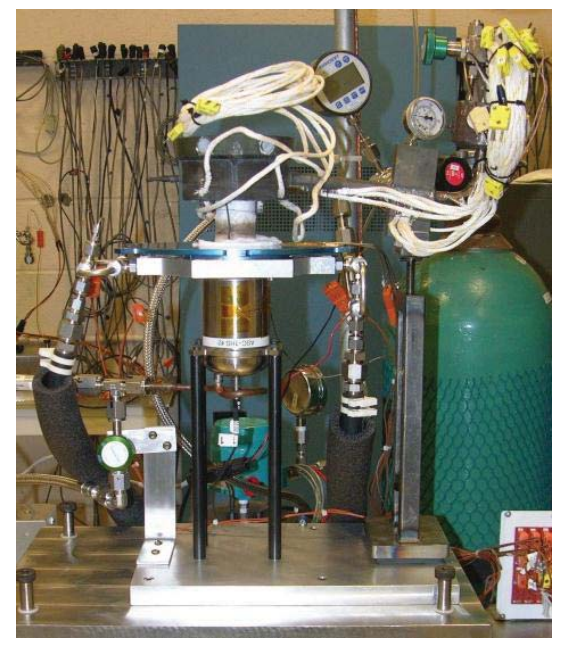

Figure 8. VCHP assembled on to the ASC-1 HS.

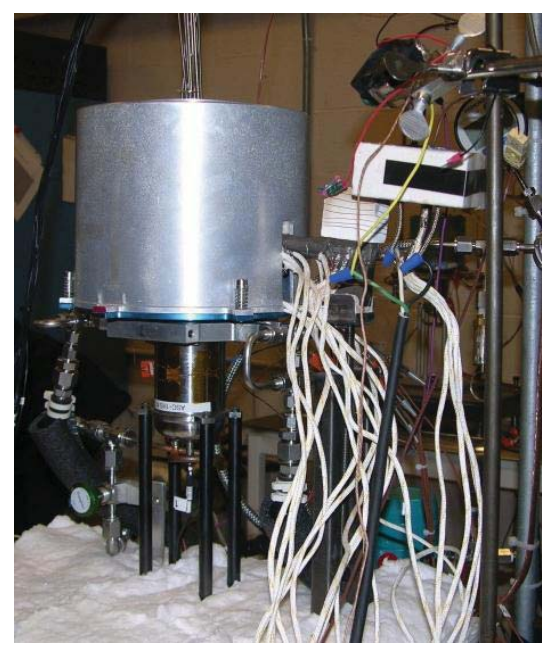

Figure 9. VCHP/ASC-1 HS with insulation.

The thermocouple (TC) map for the VCHP is shown in Figure 10. TCs 1 and 2 are probe thermocouples that are inserted into the GPHS simulator. TCs 3 through 6 read the annular vapor temperature and are spot welded on the cylindrical surface. TCs 7 through 19 are also spot welded surface TCs, four of which are located on the radiator (12 through 15). The large number of TCs on the tube and radiator section gives an accurate depiction of the front location. TC 20 is a probe that reads the NCG temperature in the reservoir. Other parameters that were monitored were the power into the cartridge heaters and the electrical power delivered from the Stirling convertor.

The GPHS is simulated with six 0.5 " diameter, 2.5 " $(64 \mathrm{~mm})$ length, $200 \mathrm{~W}$ cartridge heaters that are inserted into the nickel top of the VCHP. The heaters are made by Watlow with an Incoloy case. The NCG reservoir is heated by a 2" $(51 \mathrm{~mm})$ clamp heater wired to a PID controller to maintain a constant temperature.

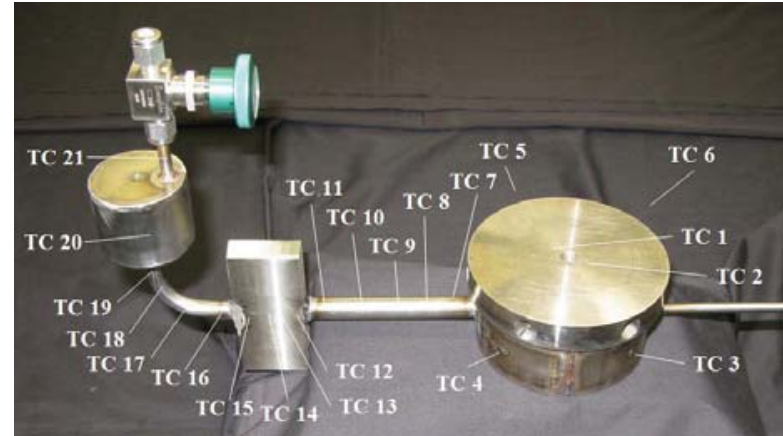

Figure 10. VCHP - Thermocouple map.

\section{Modeling}

The theoretical results for the performance of the VCHP with the Stirling are presented. The modeling is based on flat front theory and the modeling results for the four-feature and ASRG backup cooling concepts are detailed.

\section{Four Feature Theoretical Results}

The four-feature concept modeling is based on the defined operating conditions on Venus with the Stirling convertor on (feature 3). The vapor temperature of the third feature (Tv3) is set to $840{ }^{\circ} \mathrm{C}$ due to the $850{ }^{\circ} \mathrm{C}$ limit of the Stirling heater head. With the vapor temperature of the third feature defined, the required NCG mass that allows the NCG to occupy the second condenser is solved for. The NCG mass, temperature and desired position of the front determine the vapor temperature for the other features. The front position is defined by the operation of the Stirling convertor. If the convertor is on, the front is located before the second condenser. If the convertor is off, the front is located after the second condenser (radiator in use). The operating temperatures for each of the four features are shown in Figure 11 as a function of the nominal operating temperature, Tv3. The temperature for each feature is determined 
by the intersection of the vertical dashed line at $840{ }^{\circ} \mathrm{C}$. The vapor temperature of the features in test sequential order is Tv1 (transit) $774{ }^{\circ} \mathrm{C}$, Tv2 (pre-cooling) $758^{\circ} \mathrm{C}$, Tv3 (nominal) $840{ }^{\circ} \mathrm{C}$ and Tv4 (stoppage) $850{ }^{\circ} \mathrm{C}$. The coldest vapor temperature is during pre-cooling given that the Stirling will operate at a lower temperature before entry into the Venus atmosphere. The warmest predicted temperature is during the Stirling stoppage in the Venus environment at $850^{\circ} \mathrm{C}$. The actual experiment was run at lower temperatures for a safety margin from the Stirling temperature limit; Tv3 was set at approximately $814{ }^{\circ} \mathrm{C}$.

Figure 12 illustrates how the GPHS power is distributed for each feature throughout the experiment. The top dotted line is the power input into the system and the solid line is the power rejected by the VCHP radiator. The dashed line represents the power available for the Stirling convertor. The assumed losses to the environment are $68 \mathrm{~W}$ and account for the difference between the input and accepted power. The power can go to the Stirling convertor or be rejected to the environment by the VCHP radiator. The radiator is active for features 1, 2' and 4 when the convertor is off. Feature 2' is a transition from the pre-cooling stage to the nominal operation on Venus. The iteration of features 3 and 4 is to demonstrate the ability of the VCHP to handle the thermal load when the Stirling is off and to show the ability of

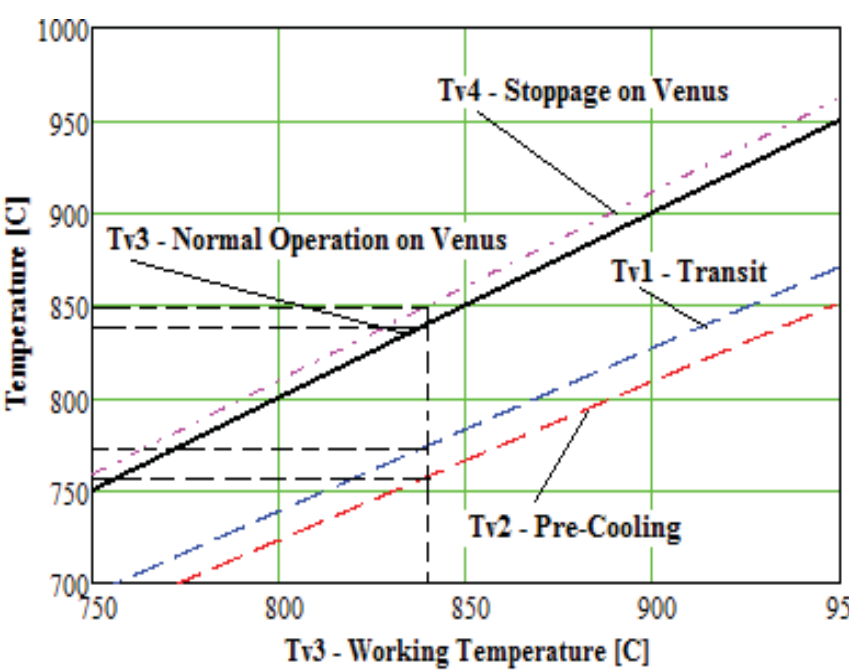

Figure 11. Feature temperatures as a function of Tv3. the system to recover in the Venus environment.

The temperature profile for the four-feature concept is shown in Figure 13. The top horizontal axis shows the corresponding feature number. The vapor temperature is shown as the top solid line, the Stirling heater head temperature is the middle dotted line and both use the left hand vertical axis.

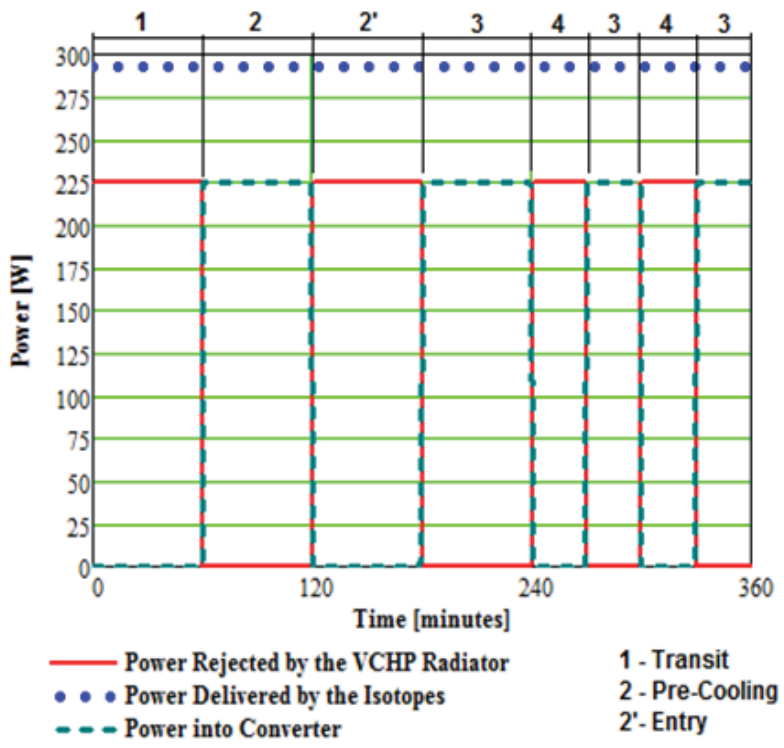

Figure 12. Power distribution versus time.

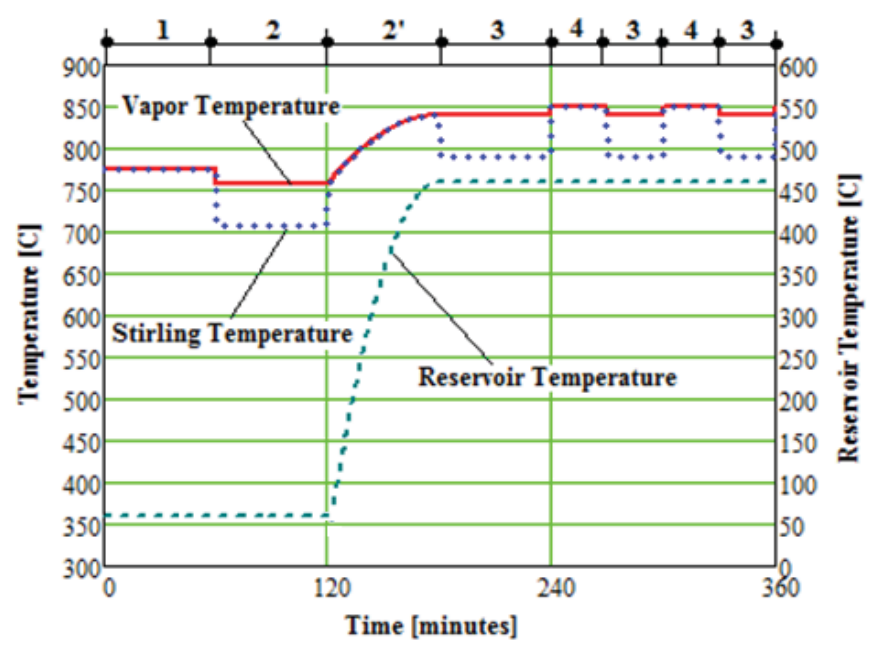

3 - Operation on Venus

4 - Stoppage on Venus

Figure 13. Four-feature concept temperatures versus time.

The reservoir temperature is shown as the bottom dashed line using the vertical right hand axis in Figure 13. The initial vapor temperature is low at $775^{\circ} \mathrm{C}$ and drops as the Stirling is used for pre-cooling. The Stirling is turned on at the start of feature 2 , slowly dropping its temperature by the temperature difference between the vapor and the 
heat collector. The Stirling is turned off and reaches the temperature of the vapor during the entry stage. A parabolic temperature profile was assumed for entry. The vapor temperature increases during the entry stage because no heat rejection occurs. The reservoir temperature increases and keeps the NCG in the second condenser. The Stirling is turned on at the start of feature 3 (nominal operation), lowering its temperature. The Stirling is turned off during feature 4, simulating a convertor stoppage in the Venus environment. Vapor temperature slightly increases to move the NCG out of the radiator while the heat collector temperature, in the absence of a heat flux, increases to that of the vapor. The on and off pattern is repeated to illustrate the potential that the VCHP offers for repeatability. The NCG reservoir temperature profile is fixed relative to the environment.

\section{ASRG Theoretical Results}

The ASRG theoretical predictions are not graphically presented as they are similar to the first and second features shown above within the four-feature concept modeling results. In the ASRG experiment, the testing sequences will start with Stirling on (feature 2) to simulate normal operation of the ASRG, followed by Stirling off (feature 1), to simulate stoppage, and again Stirling on (feature 2), to simulate a restart as well as recovery of the nominal parameters. The NCG reservoir temperature is held at approximately $100{ }^{\circ} \mathrm{C}$. The modeling results show that an 18 ${ }^{\circ} \mathrm{C}$ vapor temperature increase is required to transition from the first condenser to the second.

\section{Experimental Results}

\section{Heat Loss Determination and Convertor Calibration}

The VCHP was integrated with the Advanced Stirling Converter to determine the heat losses and to calibrate the Stirling converter. Both heat losses and calibration parameters were determined for the features where the Stirling converter is on, features 2 and 3.

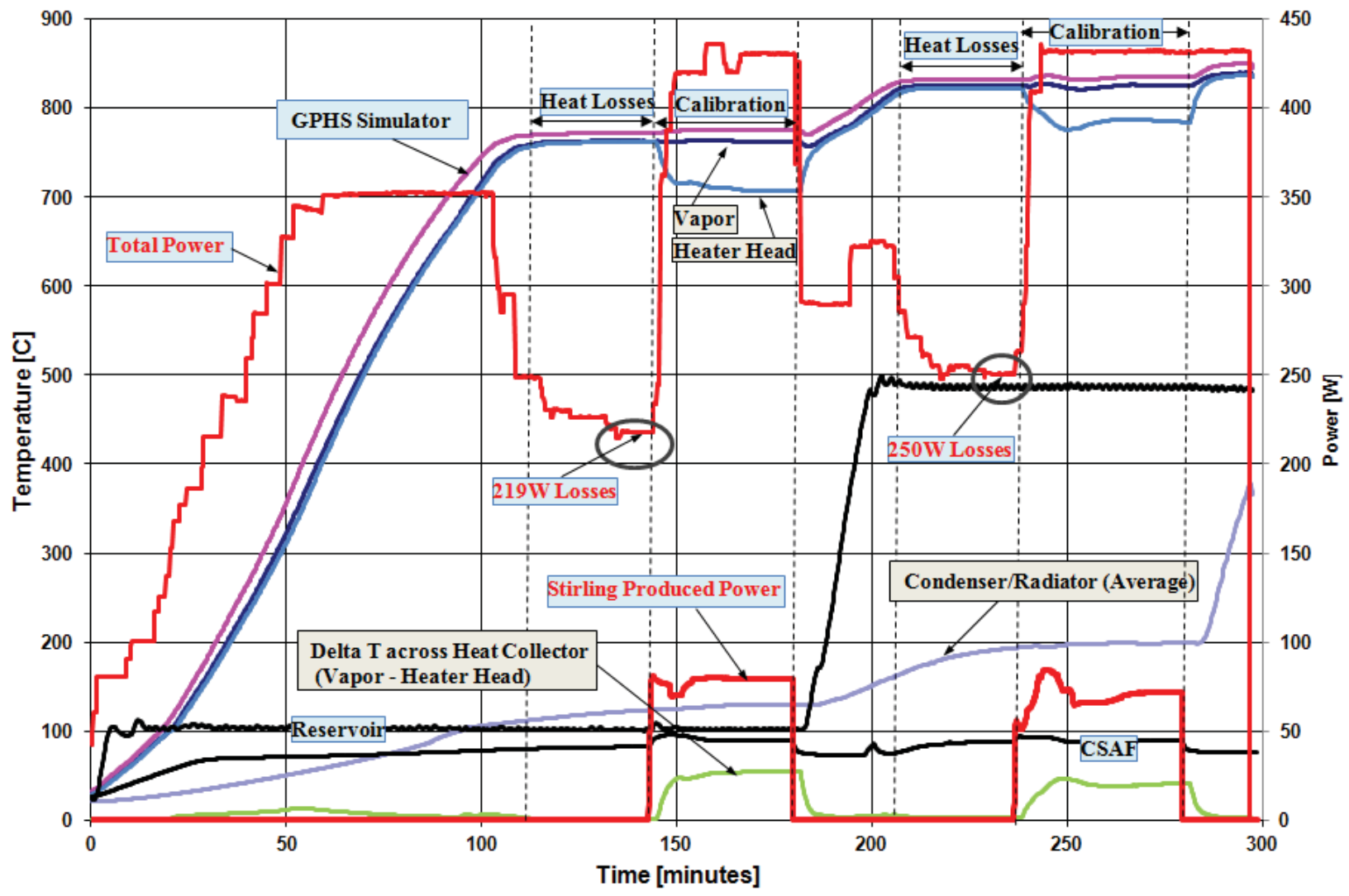

Figure 14. System heat losses and Stirling converter calibration 
Heat losses were determined by incrementally increasing the total power (electrical power from the main power supply) until steady state VCHP temperatures were obtained for each feature (2 and 3) with the Stirling converter off. The power needed to maintain the steady state temperatures for each of the two features was the heat losses for that feature. As seen in Figure 1, the heat losses were: $\sim 219 \mathrm{~W}$ in Feature 2 and $\sim 250 \mathrm{~W}$ in Feature 3. After each steady state was maintained by a power equal to heat losses, the Stirling converter was started while the total power was increased to $433 \mathrm{~W}$ resulting in a net heat accepted by the converter of $214 \mathrm{~W}$ during Feature 2 (transit) and 183 W during Feature 3 (normal operation in Venus environment). In each case, the parameters of the Stirling converter (piston amplitude, excitation voltage) were tuned/calibrated to maintain the same set points (VCHP vapor temperatures) as during the heat losses determination. Calibration results can also be observed in Figure 14 at the two VCHP vapor set points, $760 \mathrm{C}$ for Feature 2 and $820 \mathrm{C}$ for Feature 3. Part of these determinations is also valid for the ASRG Backup Cooling Concept testing since Feature 2 can represent ASRG during normal operation.

\section{ASRG Backup Cooling Concept}

The ASRG backup cooling experiment has the Stirling convertor operating at normal conditions then turns off the Stirling while still maintaining the full thermal power input to the Stirling. As previously mentioned, the VCHP in features 1 and 2 defined earlier for the Venus Lander's four-feature concept are applicable to the ASRG backup cooling concept demonstration. The test was run starting with feature 2 (Stirling on) followed by feature 1 (Stirling off) and again feature 2 to demonstrate the restart and recovery of the normal operating parameters. The temperatures and powers of interest during the experiment are shown in Figure 15. The VCHP temperatures shown are the GPHS simulator, vapor temperature and average radiator temperature. The VCHP reservoir temperature was not shown as it is constant at $101{ }^{\circ} \mathrm{C}$. The Stirling temperatures shown are for the heater head and for the cold side adapter flange (CSAF). The power produced by the Stirling is shown and references the right hand axis. The system was cycled through the three stages mentioned above: stage 1 Stirling on (20-60 min.), stage 2 Stirling off (60-150 min.), and stage 3 Stirling on (150-370 min.). The total power into the system was maintained near constant at 433 W. The results for the test focus on proving the ASRG backup cooling concept where the Stirling is able to shut down and restart at a later time being passively assisted by the VCHP.

Stage 1 starts with the Stirling on (feature 2), shown from time 20 to 60 minutes. Steady state was achieved at approximately 50 minutes. The GPHS simulator was at $774{ }^{\circ} \mathrm{C}$, the vapor at $761{ }^{\circ} \mathrm{C}$, the heater head at $702{ }^{\circ} \mathrm{C}$, the radiator at $130{ }^{\circ} \mathrm{C}$ and the $\mathrm{CSAF}$ at $89^{\circ} \mathrm{C}$. The low temperature of the radiator indicates that it is occupied by NCG and not being utilized as a condensing surface. The front is before the radiator and heat is being transferred to the Stirling. The relatively high temperature difference between the vapor and the heater head is due to thermal resistance at the VCHP - heater head interface. The power produced by the Stirling is approximately $80 \mathrm{~W}$. The heat losses through the radiator are estimated to be $3-4 \mathrm{~W}$ based on its surface area $\left(6200 \mathrm{~mm}^{2}\right)$ and temperature. 


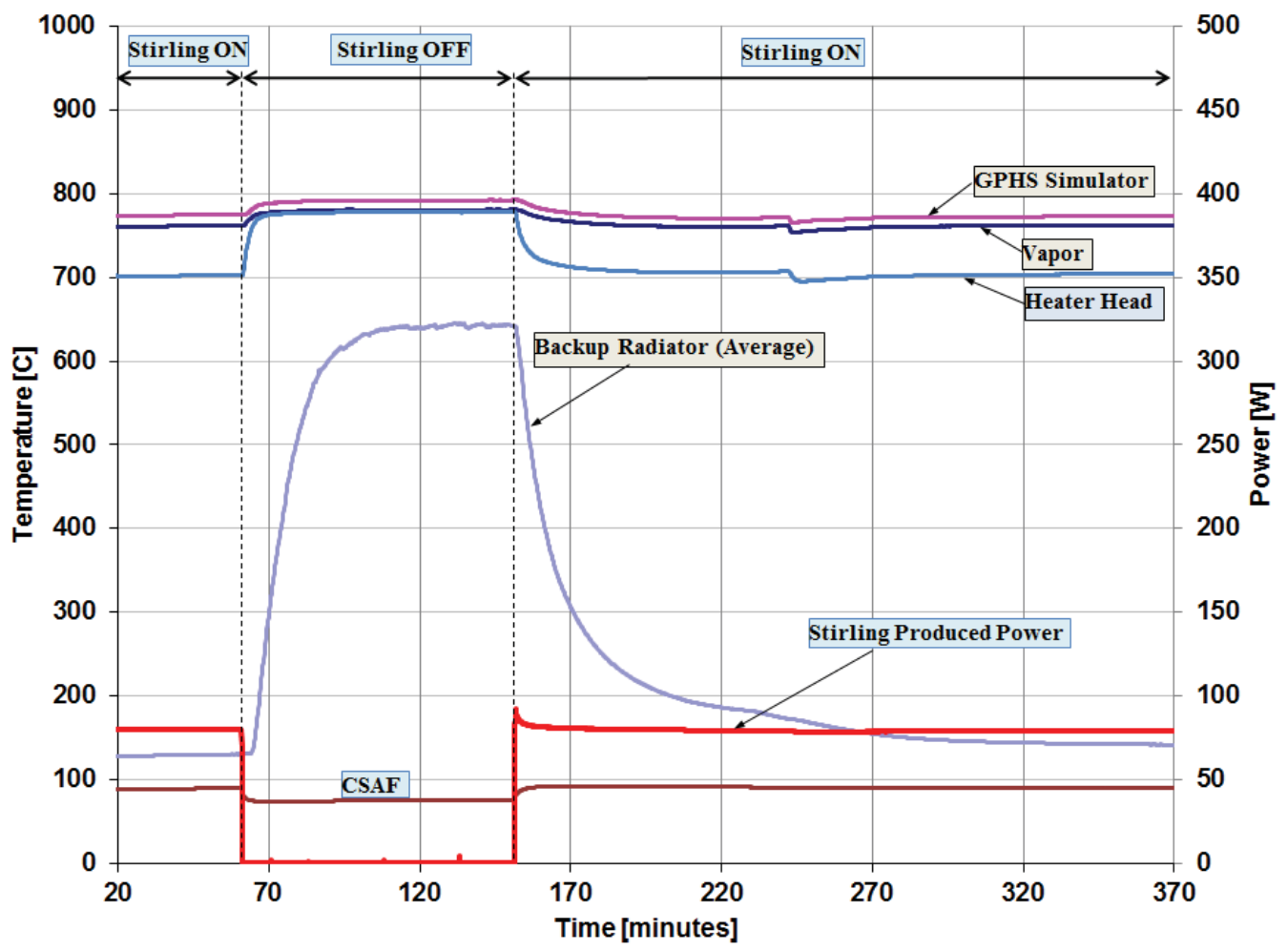

Figure 15. ASRG backup cooling concept testing - temperature profiles

The Stirling is off (feature 1) during the second stage shown from 60 to 150 minutes. The vapor temperature increased to $777{ }^{\circ} \mathrm{C}$, the heater head temperature increased to $775^{\circ} \mathrm{C}$ and the radiator starts being active. The slight rise in the vapor temperature increases the sodium vapor pressure and forces the NCG gas out of the radiator until equilibrium is reached. The radiator reached a steady state temperature of $642{ }^{\circ} \mathrm{C}$. The temperature of the heater head increased approaching the vapor temperature as the heat flux through the VCHP-heater head interface decreased to zero. The CSAF temperature decreased as the Stirling stopped rejecting waste heat to the CSAF.

The third stage (feature 2 repeat) started with turning the Stirling back on and lasted from 150 minutes to the end of the experiment ( 370 minutes). The heater head cooled rapidly as the thermal energy is being converted into electrical energy, slowly dropping the vapor temperature and condenser temperature back down to the initial values in stage 1 . The only temperature that did not return to the initial value was the average radiator temperature as the test was stopped prior to reaching a true steady state. Previous results with a Stirling heater head simulator show that the radiator does return to the initial value if the stage has a sufficient duration. The radiator temperature decreases throughout the third stage as the front retracts out of the condenser. The decrease in the vapor temperature decreased the vapor pressure and the NCG was able to reoccupy the radiator. The small drop of the GPHS simulator, sodium vapor, and heater head temperatures at 240 minutes is due to human error where the heaters were momentarily unplugged.

Figure 16 shows the power profile for the ASRG backup cooling concept testing that includes: total power into the system, power into the Stirling and power generated by the convertor. The total power is delivered by the cartridge heaters acting as the GPHS and was $433 \mathrm{~W}$. The input power to the Stirling was calculated by subtracting the heat losses previously determined from the total power output. The energy conversion efficiency of the Stirling convertor can be estimated from the input and output power shown in Figure 16. The calculated efficiency is approximately $37 \%$ aligning well with the given efficiency of $38 \%$. [4]. 


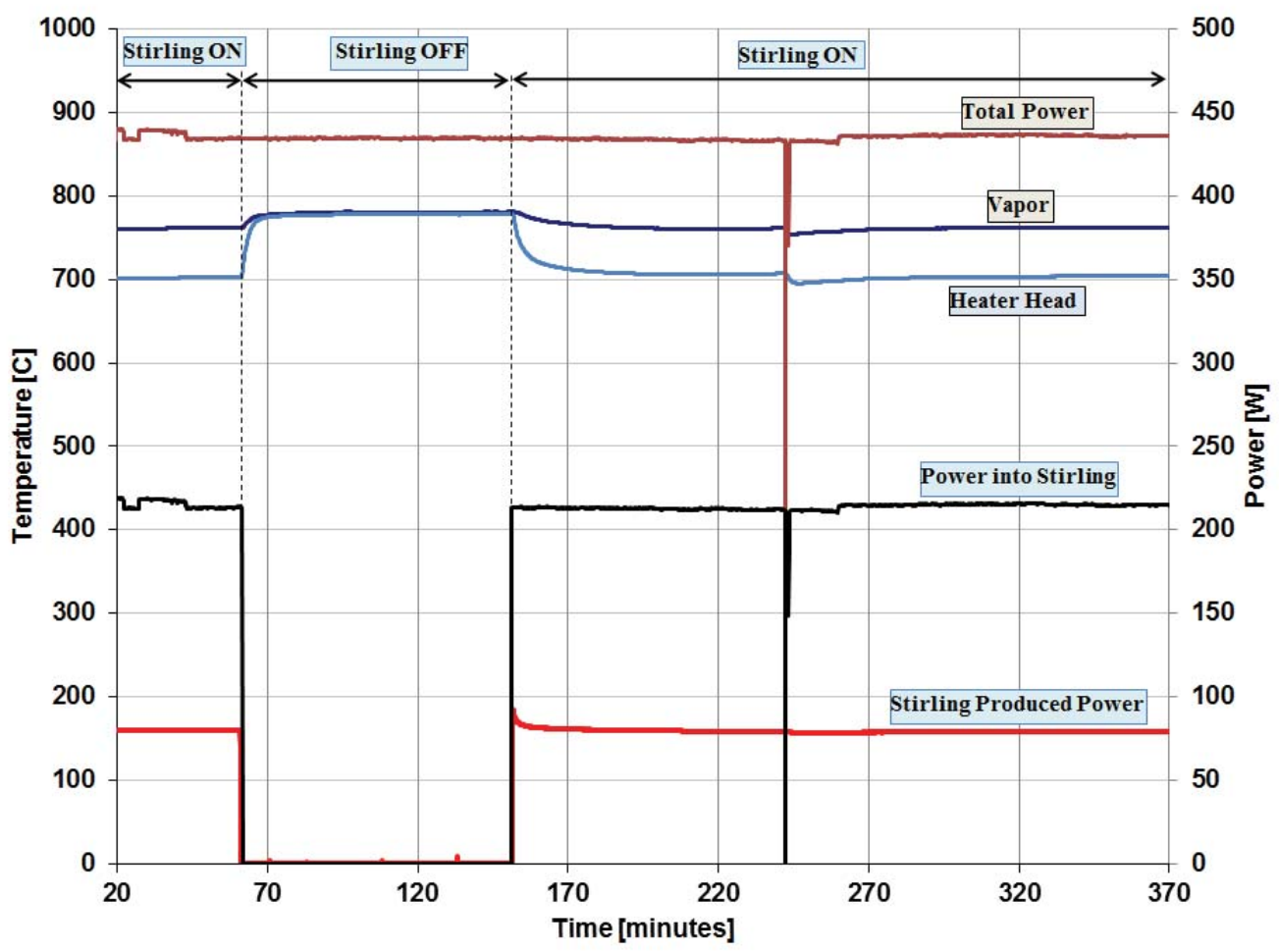

Figure 16. ASRG backup cooling concept testing - power profiles

\section{Venus Lander Four-Feature Concept}

The last part of the VCHP-Stirling testing was the Venus Lander four-feature concept demonstration. The experiment was run during a period of time ("mission" time) of approximately 500 minutes. It can be seen in Figure 17 that during the "mission" time all four features were tested. The durations of each feature are given below, in addition to the plot:

1. From 100 to 166 minutes ...Feature 1 - Transit

2. From 166 to 260 minutes ....Feature 2 - Pre-Cooling

3. From 260 to 274 minutes ....Entry (Stirling off)

4. From 274 to 360 minutes ...Feature 3 - Normal operation in Venus environment

5. From 360 to 420 minutes ...Feature 4 - Stoppage in Venus environment

6. From 420 to 500 minutes ...Feature 3 - Restart and normal operation in Venus environment

Similar to the previous concept demonstration, Figures 17 and 18 show time dependent distributions of the relevant temperatures and powers respectively. Transit (feature 1) starts with the Stirling convertor off (simulating the status during transit), where the vapor temperature is $781{ }^{\circ} \mathrm{C}$ and the radiator rejects the heat load at approximately $626^{\circ} \mathrm{C}$. The convertor is turned on at 166 minutes to start pre-cooling (feature 2). During pre-cooling, the vapor temperature decreases from $781{ }^{\circ} \mathrm{C}$ to $761{ }^{\circ} \mathrm{C}$ since the heat is now accepted by the convertor. The condenser temperature plummets as the sodium vapor pressure decreases allowing the NCG to occupy the radiator and stop the heat rejection. During the first two features, the reservoir is maintained at approximately $101^{\circ} \mathrm{C}$.

Entry into the Venus atmosphere is simulated from 260-74 minutes where, in addition to the system not rejecting heat produced by the radioisotopes, it gains ambient heat and increases its temperature in mock descent. The Stirling convertor is off during entry and the increasing temperature of the reservoir temporarily blocks the movement of the sodium to the radiator. The vapor temperature increases to $827^{\circ} \mathrm{C}$ while the reservoir temperature increases initially to approximately $485^{\circ} \mathrm{C}$. The reservoir temperature oscillation at 260 minutes is due to the heater controller having issues getting to steady state. Entry is ended by the starting of the Stirling convertor at 274 minutes. 


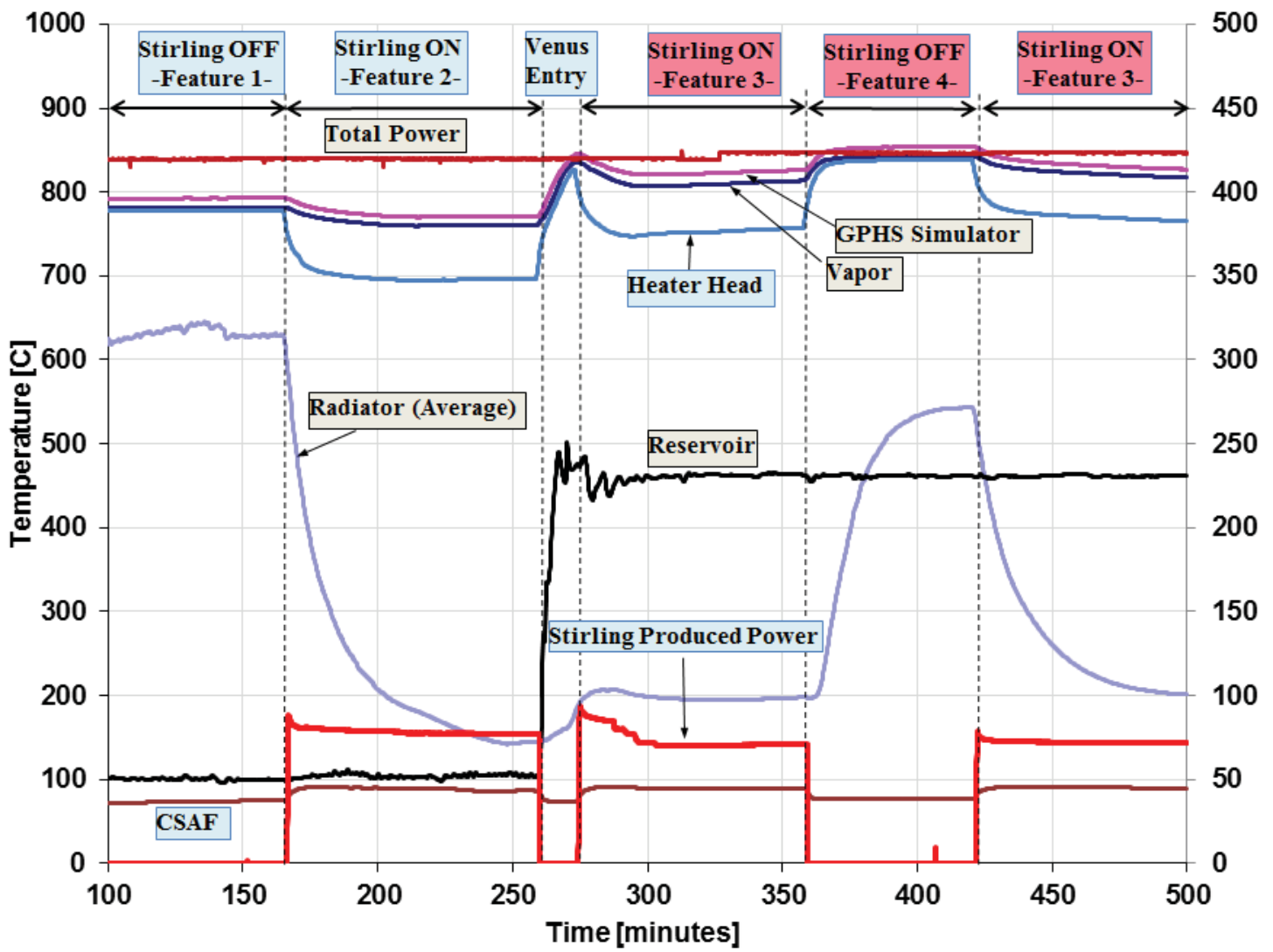

Figure 17. Venus Lander four-feature concept testing - temperature profiles.

The nominal operation in the Venus environment (feature 3) is shown from 274 to 360 minutes, where the Stirling convertor is on. The vapor, Stirling heater head and reservoir temperatures are settling at nominal values of $814^{\circ} \mathrm{C}$, $756{ }^{\circ} \mathrm{C}$ and $465{ }^{\circ} \mathrm{C}$ respectively. The stoppage on Venus (feature 4) starts at 360 minutes by turning off the Stirling convertor. Consequently, the vapor temperature increases to $839{ }^{\circ} \mathrm{C}$, activating the radiator that reaches a temperature of approximately $542{ }^{\circ} \mathrm{C}$ as it rejects the heat that was input. Feature 4 was run for a long duration to obtain an approximate steady state value of the radiator. The radiator does not achieve the same temperature as during transit (feature 1) as the heat losses are higher for the whole system and consequently the power rejected during stoppage is lower.

After the stoppage, the Stirling convertor is restarted and the system parameters return to values corresponding to normal operation in the Venus environment (feature 3). The radiator temperature decreases rapidly as the convertor now accepts heat and the front retracts. The sodium cools down slightly and the NCG forces the sodium out of the radiator. It can be observed that during the entire mission, the temperature drop between the vapor and the heater head when Stirling was on was around $65{ }^{\circ} \mathrm{C}$ during pre-cooling (feature 2) and around $56{ }^{\circ} \mathrm{C}$ during normal operation in the Venus environment (feature 3). This difference is due to the fact that during pre-cooling, heat losses are lower than during normal operation so the heat flux through the interface is higher. As a general conclusion, the system worked reasonably close to the predicted parameters confirming the concept, however, the stoppage (feature 4) could have been longer to ensure a steady state radiator temperature.

Figure 18 shows separately the power profile for the four-feature concept test including: total power into the system, power into the Stirling and electrical power generated. Again, the input power into the Stirling convertor was calculated by subtracting the heat losses through insulation from the total power delivered by the heaters. As mentioned before, the heat losses were previously determined as $219 \mathrm{~W}$ during pre-cooling (vapor temperature of $762{ }^{\circ} \mathrm{C}$ ) and approximately $250 \mathrm{~W}$ during normal operation in Venus environment (vapor temperature of $814^{\circ} \mathrm{C}$ ). The steady state temperature distributions along the VCHP are also shown in Figure19 for all the features. 


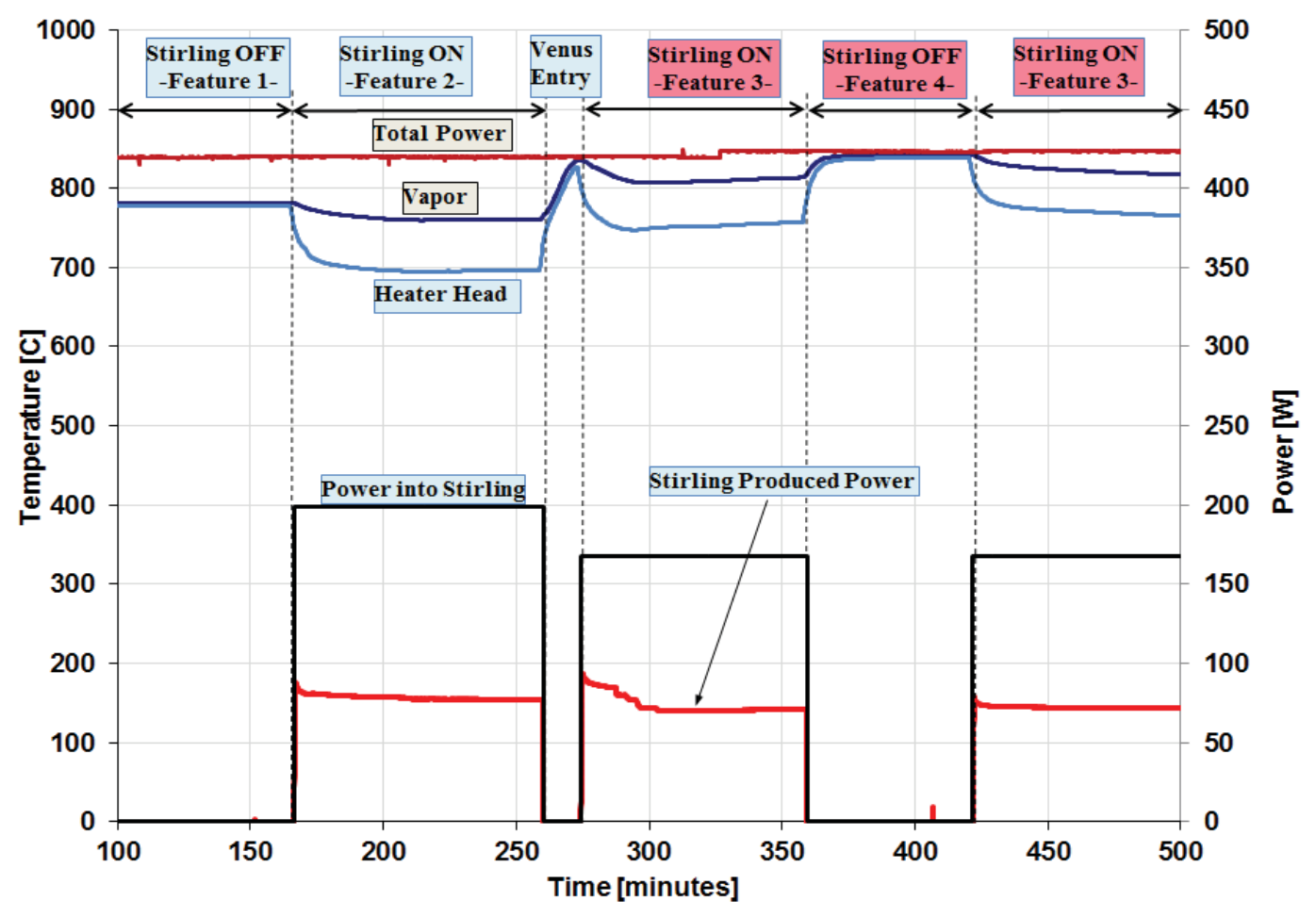

Figure 18. Four Feature power profile

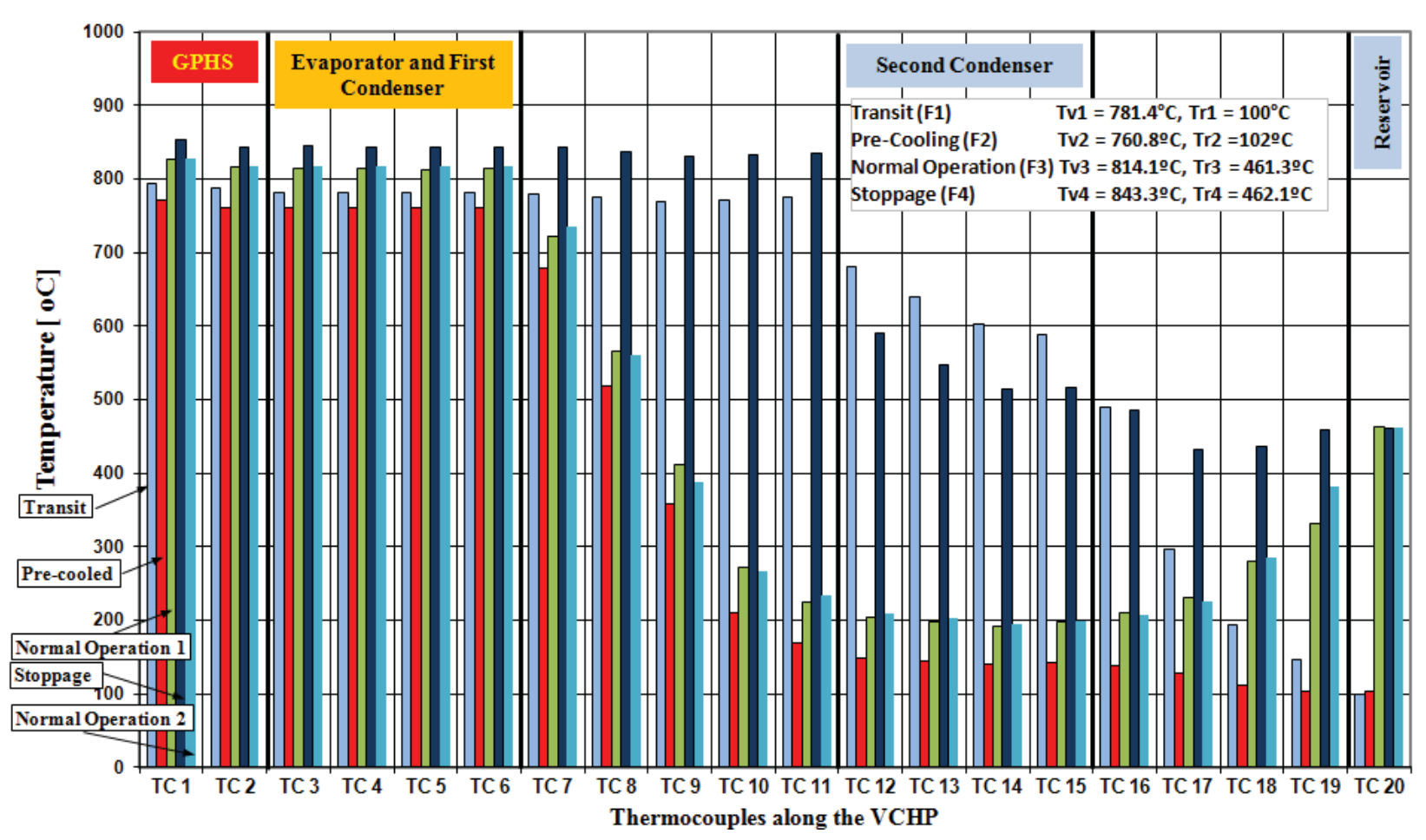

Figure 19. Four Feature Concept - Experimental results with Stirling converter: Steady state temperature distributions along the VCHP for all four features. 


\section{Conclusion}

The VCHP was successfully tested with a high temperature Stirling convertor, all test objectives were achieved demonstrating proof-of-concept of ACT's heat pipe. The joint NASA/ACT test marks the first successful operation of a hot-end VCHP with a Stirling convertor. The VCHP was able to successfully demonstrate both the ASRG back up cooling concept and the Venus Lander four-feature concept with a Stirling convertor at NASA Glenn Research Center. In the ASRG back up cooling concept, the VCHP allowed the Stirling to be shut off with a minimum rise in the heater head temperature (approximately $16{ }^{\circ} \mathrm{C}$ ) and to be restarted to achieve the initial condition. The Venus Lander four-feature concept testing illustrated the ability of the VCHP to passively operate as predicted for each feature. Good agreement was found between the model and the experimental results with only small discrepancies. The feasibility of using an alkali metal VCHP as the backup or primary cooling system for a Stirling convertor has been proven experimentally.

\section{Nomenclature}

$$
\begin{array}{ll}
T r & =\text { reservoir temperature } \\
T v & =\text { vapor temperature }
\end{array}
$$

\section{Acronyms}

ASC, Advanced Stirling Convertor

ASRG, Advanced Stirling Radioisotope Generator

CSAF, Cold Side Adapter Flange

GPHS, General Purpose Heat Source

GRC, Glenn Research Center

NCG, Non Condensable Gas

PID, Proportional Integral Derivate

MLI, Multi-Layer Insulation

RPS, Radioisotope Power System

TC, Thermocouple

VCHP, Variable Conductance Heat Pipe

\section{Acknowledgments}

This research was sponsored by NASA Glenn Research Center under Contract No. NNX11CA59C. Any opinions, findings, and conclusions or recommendations expressed in this article are those of the authors and do not necessarily reflect the views of the National Aeronautics and Space Administration. Rodger Dyson was the contract technical monitor. Tim Wagner was ACT's technician for the program and constructed the VCHP prototype.

\section{References}

[1] J. Chan, J. G. Wood and J. G. Schreiber, "Development of Advanced Stirling Radioisotope Generator for Space," STAIF, Albuquerque, 2007.

[2] C. Tarau and W. G. Anderson, "Sodium Variable Conductance Heat Pipe for Radioisotope Stirling Systems Design and Experimental Results," IECEC, Nashville, 2010.

[3] C. Tarau, W. G. Anderson and C. J. Peters, "Variable Conductance Heat Pipes for Long-Lived Venus Landers," Journal of the British Interplanetary Society, vol. 63, no. 9/10, pp. 336-344, 2011.

[4] P. A. Cornell, . E. J. Lewandowski, S. M. Oriti and S. D. Wilson, "Stirling Convertor Extended Operation Testing and Data Analysis at Glenn Research Center," IECEC, Denver, 2009. 